\title{
Formulation and Evaluation of FSM-Alginate Beads of Vildagliptin
}

\author{
Abiya Sara Cherian * Boby Johns G, Praveen Raj R, Daisy P.A, Jeny Samuel \\ Department of Pharmaceutics, St Joseph's College of Pharmacy Chertahla, Alappuzha, Kerala, India, - 688524
}

\begin{abstract}
Many approaches have been immerged to prolong the residence time of the dosage forms at the absorption site .One among them is the development of oral controlled release mucoadhesive system. The present study aims to formulate and evaluate the effectiveness of FSMAlginate beads of Vildagliptin in streptozotocin induced diabetic rats. In the present work, 6 formulations of Vildagliptin mucoadhesive beads (F1 to F6) were prepared by ionotropic gelation method. Fenugreek seed mucilage and sodium alginate was used as polymers and calcium chloride as cross linking agent. The beads containing drugs and excipients were subjected to various evaluation test such as Particle size distribution, Swelling index, Mucoadhesivity and Dissolution studies. Among all the formulations, F3 containing FSM and sodium alginate in the concentration of $0.6 \mathrm{~g}$ and \% DEE of 97.89 resulting in the highest drug release rate of $97.86 \%$ at the end of $10 \mathrm{~h}$. Hence, it was considered as the optimized formulation.
\end{abstract}

Keywords: Mucoadhesion, Fenugreek Seed Mucilage, Sodium Alginate, Diabetes. Ionotropic Gelation.

Article Info: Received 14 July 2019; Review Completed 23 Aug 2019; Accepted 27 Aug 2019; Available online 30 Aug 2019

Cite this article as:

Cherian AS, Boby Johns G, Praveen Raj R, Daisy P.A, Jeny S, Formulation and Evaluation of FSM-Alginate Beads of Vildagliptin, Journal of Drug Delivery and Therapeutics. 2019; 9(4-A):246-251 http://dx.doi.org/10.22270/jddt.v9i4A.3289

*Address for Correspondence:

Email: 1994abisara@gmail.com

\section{INTRODUCTION:}

Over the previous few decades, a great deal of interest has been paid to the development of polysaccharide-based hydrogel beads thru ionotropic gelation technique, which are useful as achievable carriers in controlled drug delivery. The benefit of physical cross-linking by way of ionotropic gelation is that the drug encapsulation in the beads could be carried out in an eco-friendly environment avoiding the feasible toxicity of reagents associated with chemical crosslinking. To formulate numerous cross-linked alginate mucoadhesive systems for controlled-release drug delivery, use of mucoadhesive polymer-blend with alginate is one of the generally accepted approaches. Again, blending with suitable polymer can enhance drug encapsulation and stability, which are found lower in cross-linked alginate hydrogel beads processed by ionotropic gelation.

FSM was obtained from Trigonella foenum-graecum L. seeds known as Methi and is a commonly reachable material in nature. Fenugreek seeds comprise a high percentage of mucilage. The pharmaceutical utility of FSM is already established as mucoadhesive gelling agent, binding agent, and disintegrating agent. It is additionally suggested that the FSM has antidiabetic property .In the present study, the utility of FSM, as a possible herbal mucoadhesive polymericblend with sodium alginate for the development of a novel mucoadhesive beads through ionotropic gelation technique for the use in oral delivery was evaluated using Vildagliptin as model drug. [1, 2,3]

Vildagliptin is a new oral antidiabetic drug that enhances pancreatic islet cell responsiveness to glucose. Vildagliptin trade names Galvus, Zomelis,) is an oral anti-hyperglycemic agent (anti-diabetic drug) of the dipeptidyl peptidase-4 (DPP- 4) inhibitor classification of drugs. Vildagliptin inhibits the inactivation of GLP-1and GIP via DPP-4, permitting GLP-1 and GIP to potentiate the secretion of insulin in the beta cells and suppress glucagon release by using the alpha cells of the islets of Langerhans in the pancreas. Vildagliptin has been shown to limit hyperglycemia in type 2 diabetes mellitus. Biological half-life 2-4 hrs. Main site of absorption is at small intestine. Therefore, the study used to be planned with an aim of developing a herbal polysaccharide-based more than one unit mucoadhesive system of Vildagliptin by the use of sodium alginate-FSM polymer-blend for controlled-release oral drug delivery $[4,5]$.

\section{MATERIALS AND METHODS}

\subsection{Materials}

Vildagliptin (Yarrow Chem Products, Mumbai), Sodium Alginate (Loba Chemi India), Calcium Chloride (Nice 
Chemicals) and Fenugreek seeds were collected from Chertahla in the month of February 2019. All the reagents and chemicals are of analytical grade.

\subsection{Extraction and purification of Fenugreek Seed Mucilage:}

Seeds are washed to get rid of dirt and particles. The fenugreek seeds $(250 \mathrm{~g})$ had been soaked in distilled water $(500 \mathrm{ml})$ overnight time and heated at $50^{\circ} \mathrm{C}$ for 2 hours. The mucilage is extracted using multilayer material bag to take away the mare from the solution. Acetone was added to the above filtrate to precipitate the mucilage and therefor the mucilage was separated, dried in an oven at $50^{\circ} \mathrm{C}$, keep in desiccator until use. The acquired powder was re-dissolved in a hundred $\mathrm{ml}$ of water, filtered and centrifuged for 20 minutes at $3000 \mathrm{rpm}$.The supernatant clear answer was evaporated and dried. The purified stable mass was dried and saved in an air tight container.[1,17]

\section{3_Preparation of FSM -alginate beads containing Vildagliptin}

The mucoadhesive beads could be prepared via Ionotropic Gelation Method (IG). Sodium alginate and FSM aqueous dispersions were organized separately by using of distilled water. With a magnetic stirrer, these dispersions were well blended with stirring at 200-400 rpm for $10 \mathrm{~min}$. Vildagliptin was then added to the dispersion aggregate. Using magnetic stirrer, drug and polymers will be dissolved entirely in water. The stirring is sustained until clear dispersion is formed, then this dispersion is dropped through a satisfactory needle $21-\mathrm{G}$ in to calcium chloride $(\mathrm{CaCl} 2)$ solution. In the $\mathrm{CaCl} 2$ solution, the added droplets were retained for $15 \mathrm{~min}$ to complete the healing reaction and to produce rigid beads. The beads was filtered, washed with distilled water and dried at room temperature.

Table 1 Formulation Chart.

\begin{tabular}{|l|c|c|c|c|c|c|}
\hline INGREDIENTS(mg) & F1 & F2 & F3 & F4 & F5 & F6 \\
\hline VILDAGLIPTIN & 500 & 500 & 500 & 500 & 500 & 500 \\
\hline SODIUM ALGINATE & 100 & 200 & 300 & 400 & 500 & 600 \\
\hline FSM MUCILAGE & 100 & 200 & 300 & 400 & 500 & 600 \\
\hline CALCIUM CHLORIDE & 2 & 2 & 2 & 2 & 2 & 2 \\
\hline
\end{tabular}

\subsection{CHARECTERIZATION METHODS}

\subsubsection{Fourier Transform Infra-Red Spectroscopy:}

The compatibility between pure drug and polymer was detected by FT-IR spectra obtained. Samples were reduced to powder and analyzed as $\mathrm{KBr}$ pellets by employing a Fourier transform-infrared (FTIR) spectroscope (Perkin Elmer Spectrum RX I, USA). The pellet was placed within the sample holder. Spectral scanning was taken within the wavelength region between 4000 and $400 \mathrm{~cm}-1$ at a resolution of $4 \mathrm{~cm}-1$ with scan speed of $1 \mathrm{~cm} / \mathrm{s}$.

\subsubsection{Surface Morphology Analysis by Scanning Electron Microscopy (SEM):}

Beads having drug were gold coated by mounted on a brass stub using double-sided adhesive tape and under vacuum in an ion sputter with a tiny layer of gold $(3-5 \mathrm{~nm})$ for $75 \mathrm{~s}$ and at $20 \mathrm{kV}$ to make them electrically conductive and their morphology was observed by scanning electron microscope (ZEISS EVO 40, Japan).

\subsubsection{Bead Size Measurement}

Particle size of 100 dried beads from every batch was measured by optical microscopic technique for average particle size using an optical microscope (Olympus). The ocular micrometer was formerly calibrated by stage micrometer.

\subsubsection{Determination of DEE}

$100 \mathrm{mg}$ of beads were taken and were crushed using pestle and mortar. The crushed powders of drug containing beads were placed in a very $250 \mathrm{ml}$ volumetric flask and the volume was made up to $250 \mathrm{ml}$ by phosphate buffer, $\mathrm{pH} 7.4$, and kept for $24 \mathrm{~h}$ with infrequently shaking at $37 \pm 0.5 \circ \mathrm{C}$. After the specified time, the mixture was stirred at $500 \mathrm{rpm}$ for 20 min by means of a magnetic stirrer (Remi Motors, India). The polymer debris fashioned after disintegration of bead was removed by filtering through Whatman ${ }^{\circledR}$ filter paper (No. 40). The drug content within the filtrate was determined using a UV-vis spectrophotometer (Shimadzu,
Japan) at $233 \mathrm{~nm}$ against acceptable blank. The DEE (\%) of these prepared beads was calculated by the subsequent formula.

$$
\text { DEE }(\%)=: \frac{\text { Actual drug content in beads }}{\text { Theoritical drug content in beads }} * 100
$$

\subsubsection{Evaluation of Swelling Behavior}

Swelling behavior analysis of beads containing drug were carried out in two different aqueous media: $0.1 \mathrm{~N} \mathrm{HCl}(\mathrm{pH}$ 1.2), and phosphate buffer ( $\mathrm{pH}$ 7.4). $100 \mathrm{mg}$ beads were placed in vessels of dissolution equipment (Campbell Electronics, India) containing $500 \mathrm{ml}$ corresponding media. The experiment was carried out at $37 \pm 1 \circ \mathrm{C}$ under $50 \mathrm{rpm}$ paddle speed. The swelled beads were removed at scheduled time interval and weighed after drying the surface, by using a tissue paper. Swelling index was resolved by using the following formula:

$$
\begin{aligned}
& \text { Swelling index } \\
& \text { Weight of beads after swelling - Dry weight of bead }
\end{aligned} * 100
$$

\subsubsection{Ex- vivo Mucoadhesion Testing.}

The mucoadhesive properties of beads containing drug were evaluated by ex vivo wash-off methodology. Freshly excised pieces of goat intestinal mucosa $(2 \mathrm{~cm} \times 2 \mathrm{~cm}$ ) (collected from slaughterhouse) were mounted on glass slide $(7.5 \mathrm{~cm} \times$ $2.5 \mathrm{~cm}$ ) using thread. About 50 beads were unfold onto the wet tissue specimen, and the prepared slide was slung onto a groove of disintegration test apparatus. The tissue specimen was given a even up and down movement in a vessel containing $900 \mathrm{ml}$ of $0.1 \mathrm{~N} \mathrm{HCl}(\mathrm{pH} \mathrm{1.2)}$ and phosphate buffer ( $\mathrm{pH} 7.4$ ), separately, at $37 \pm 0.5 \circ \mathrm{C}$. After regular time intervals, the machine was stopped and therefore the range of beads still adhering to the tissue was counted.

\subsubsection{In Vitro Drug Release Studies.}

The release of drug from numerous beads was tested using dissolution equipment USP (Campbell Electronics, India) The baskets were enclosed with 100-mesh nylon cloth to 
stop the seepage of the beads. The dissolution rates were measured at $37 \pm 1 \circ \mathrm{C}$ under $50 \mathrm{rpm}$ speed. Accurately weighed quantities of beads containing Vildagliptin equivalent to $100 \mathrm{mg}$ were added to $900 \mathrm{ml}$ of $0.1 \mathrm{~N} \mathrm{HCl} \mathrm{(pH}$ 1.2). The test was carried out for $2 \mathrm{~h}$ and then continued in phosphate buffer ( $\mathrm{pH} 7.4$ ) for next $8 \mathrm{~h} .5 \mathrm{ml}$ of aliquots was collected at regular time intervals, and therefore the same quantity of fresh dissolution medium was replaced into dissolution vessel to keep the sink condition throughout the experiment. The collected aliquots were filtered, and suitably diluted to determine the absorbance using a UV-vis spectrophotometer (Shimadzu, Japan) at $233 \mathrm{~nm}$ against suitable blank.

\subsubsection{Drug Release Kinetic Data}

In order to understand the kinetics and mechanism of drug release, the result of in-vitro drug release study of beads were fitted with various kinetic equation like zero order (cumulative \% release vs. time), Kosmeyer Peppas model ,Higuchi's model (cumulative \% drug release vs. square root of time). $\mathrm{R}^{2}$ values were calculated for the linear curve obtained by regression analysis of the above plots.

Table 2: Results of various studies like particle size determination, \%DEE and in-vitro drug release

\begin{tabular}{|c|c|c|c|c|}
\hline SINO & FORMULATION CODE & $\begin{array}{c}\text { MEAN PARTICLE } \\
\text { SIZE(mm) }\end{array}$ & \%DEE & \%DRUG RELEASE \\
\hline 1 & F1 & 1.37 & 96.45 & 96.42 \\
\hline 2 & F2 & 1.35 & 95.29 & 94.20 \\
\hline 3 & F3 & 1.28 & 97.89 & 97.86 \\
\hline 4 & F4 & 1.36 & 96.65 & 96.49 \\
\hline 5 & F5 & 1.37 & 95.49 & 94.74 \\
\hline 6 & F6 & 1.39 & 95.86 & 95.76 \\
\hline
\end{tabular}

\section{RESULTS AND DISCUSSION}

\subsection{Fourier Transform Infra-Red Spectroscopy:}

The FTIR spectra of Sodium alginate, FSM, Vildagliptin and FSM alginate bead contain Vildagliptin were shown in the figure 1. The FTIR spectra of sodium alginate showed the band around 3440.92, 2931.73, 2160.23, 1620.18, 1419.59, and $1033.84 \mathrm{~cm}^{-1}$ which are due to the stretching of $\mathrm{OH}$
$, \mathrm{CH}, \mathrm{C}=\mathrm{C}, \mathrm{CF}, \mathrm{CBr},=\mathrm{C}-\mathrm{H}$ respectively. FTIR spectrum of isolated FSM showed characteristic peaks of $-\mathrm{OH}$ between 3511.6 and $3154.3 \mathrm{~cm}-1,-\mathrm{CH} 3$ at $2925.48 \mathrm{~cm}-1,-\mathrm{CH}$ stretching between 2920.0 and $2854.1 \mathrm{~cm}-1$, ether linkage at $1455-$ $1400 \mathrm{~cm}-1$ and-CO stretching at $1017.7 \mathrm{~cm}-1$.Absence of peaks indicates that there were no interaction among the polymers.
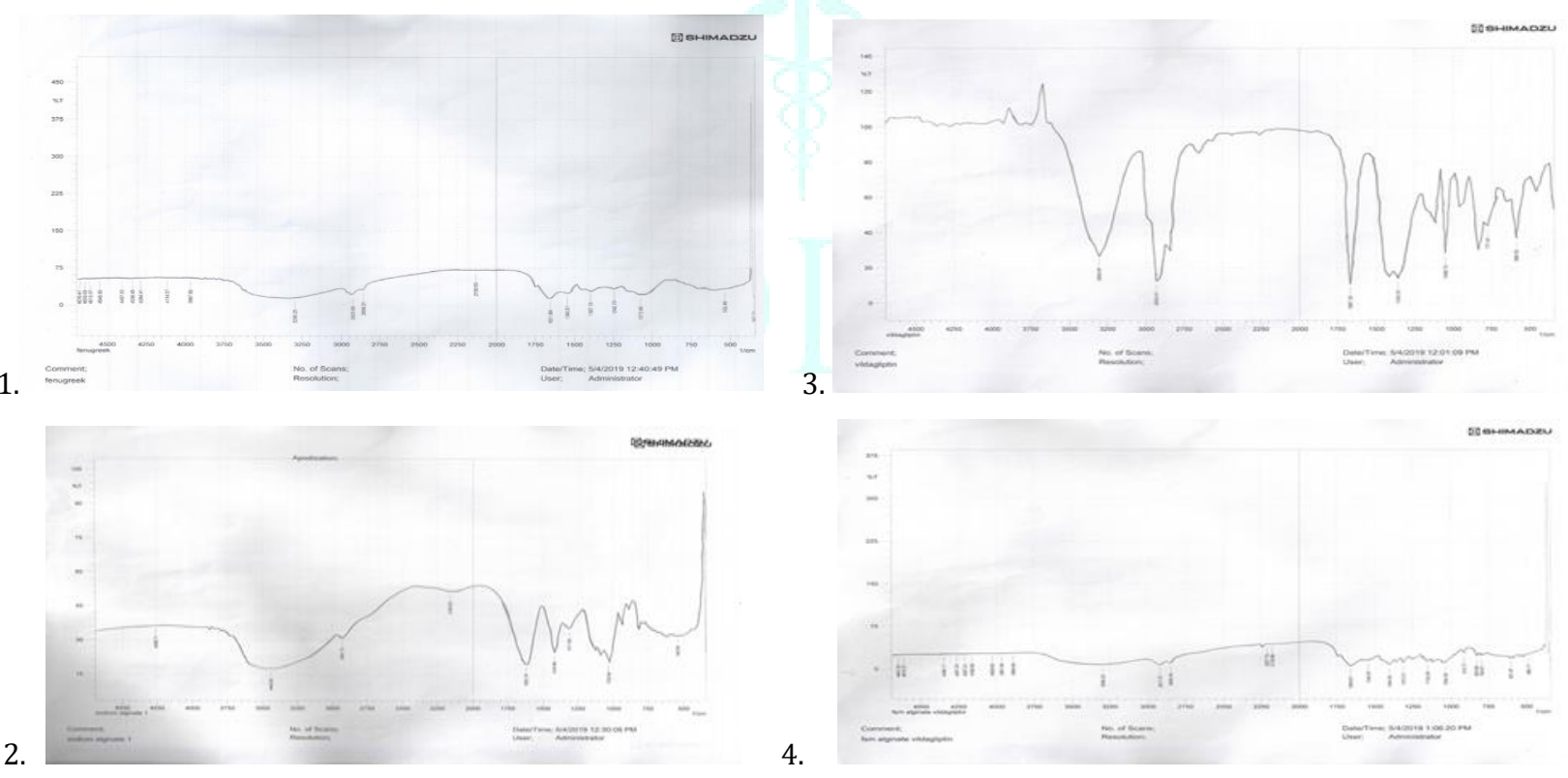

Fig:1 FTIR Spectrum 1: Vildagliptin,2:Sodim Alginate,3:FSM,4: Drug Polymer Mixture. 


\subsection{Surface Morphology Analysis by Scanning Electron Microscopy (SEM Analysis)}

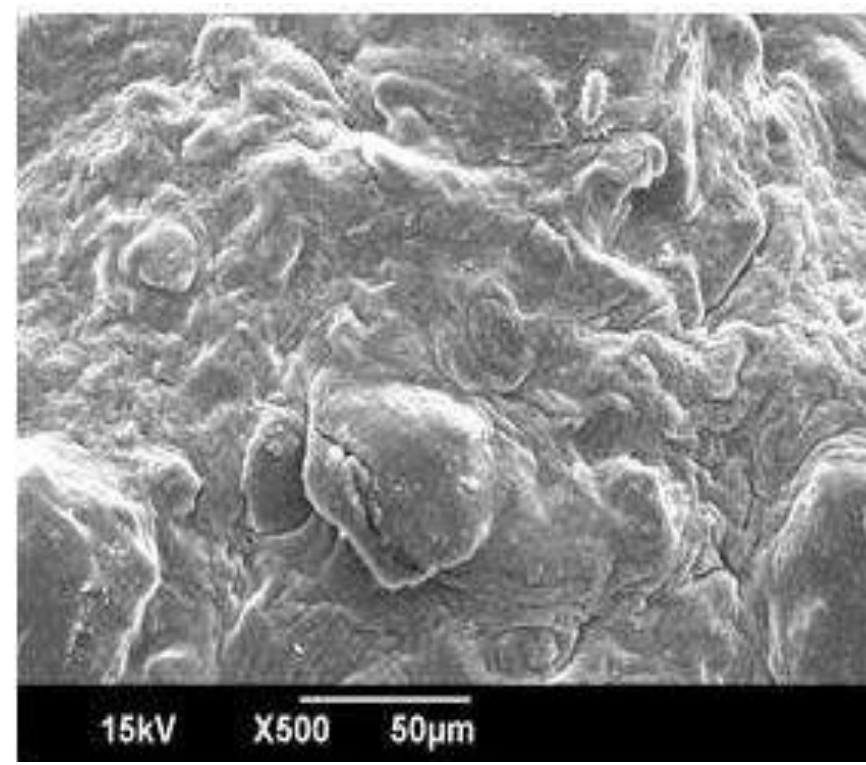

Fig.2 Scanning electron photograph of optimized FSMAlginate bead containing Vildagliptin.

The SEM photograph of the surface of the FSM-alginate bead of Vildagliptin (Fig. 2) exhibited very hard surface with characteristic massive wrinkles and cracks. These cracks and wrinkles may be caused via partly collapsing the polymeric gel network during drying. Due to the migration of beads along with water to the surface during drying will result in the formation of drug crystals.

\subsection{Bead Size Measurement.}

Particle of FSM-alginate beads of Vildagliptin was within the range of $1.28-1.39 \mathrm{~mm}$. Increasing the incorporation of FSM in the polymer solution with sodium alginate will increase the size of beads. Due to the increase in viscosity of the polymer blend solution with the addition of FSM in increasing ratio in turn increase the droplet size. A decrease in particle size of FSM alginate beads was seen when concentrated calcium chloride was used as cross linking agent.

\subsection{Determination of DEE}

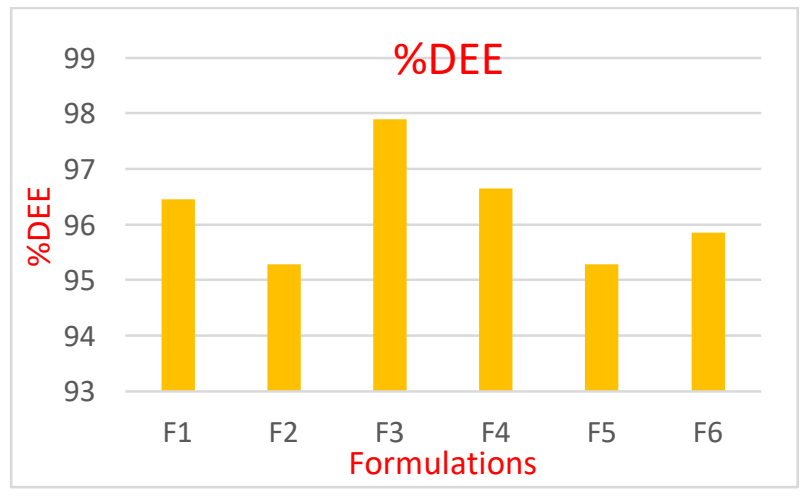

Fig.3: Drug encapsulation efficiency of F1-F6 formulations.

The drug encapsulation of beads was within the range of 95.29 - 97.89. When the sodium alginate to FSM ratio in the polymer blend decreases, DEE \% was increased. This may be due to the viscosity variations in the polymer blend. Thus the leaching of the drug to the polymeric solution will be prevented during the time of cross linking.

\subsection{Evaluation of Swelling Behavior.}

Swelling behavior of optimized formulation F3 was carried out in 2 different medias.0.1N HCL pH1.2 and phosphate buffer pH7.4.When compared with phosphate buffer swelling behavior of FSM-alginate beads containing Vildagliptin was lower in acidic medium. This is because of the shrinkage of alginate at acidic medium.

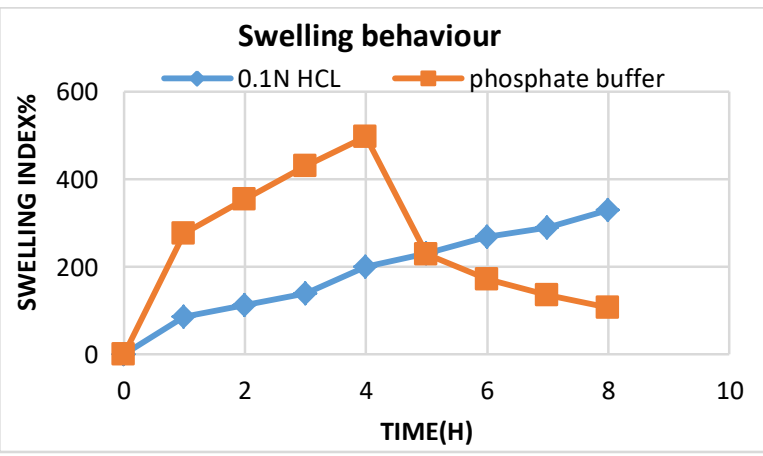

Fig.4 Swelling behavior of optimized formulation F3.

Maximum swelling was observed in 3-4 hours in phosphate medium after that erosion and dissolution takes place. It has been previously reported that the swelling of calcium alginate in presence of calcium ion capturing agent depends on the progressive displacement of calcium ions within calcium alginate-based beads. It has been also reported that the swelling of calcium alginate-based beads can be enhanced by the presence of phosphate ions (in phosphate buffer), which act as calcium sequestrant. Thus this results clearly suggest that FSM -alginate beads containing Vildagliptin may slightly swell in the stomach and move to the upper intestine and the Vildagliptin is to be absorbed.

\subsection{Ex- vivo Mucoadhesion Testing}

The ex vivo wash off test using goat intestinal mucosa for assessing Mucoadhesivity of FSM-alginate beads containing Vildagliptin was once performed at each gastric $\mathrm{pH}(0.1 \mathrm{~N}$ $\mathrm{HCl}, \mathrm{pH} 1.2$ ) and intestinal $\mathrm{pH}$ (phosphate buffer, $\mathrm{pH}$ 7.4) for eight $\mathrm{h}$. The wash off used to be faster at intestinal $\mathrm{pH}$ than at gastric $\mathrm{pH}$. In acidic $\mathrm{pH}$ the percentage of beads adhere to the mucosal tissue varied from $70-87 \%$ in acidic buffer and $90-50 \%$ in alkaline buffer. The decreased Mucoadhesion of FSM-alginate beads containing Vildagliptin in phosphate buffer may be resulted due to the erosion of calcium ion. Therefore, the results of the wash off test indicated that the FSM-alginate beads containing Vildagliptin possessed good mucoadhesivity.

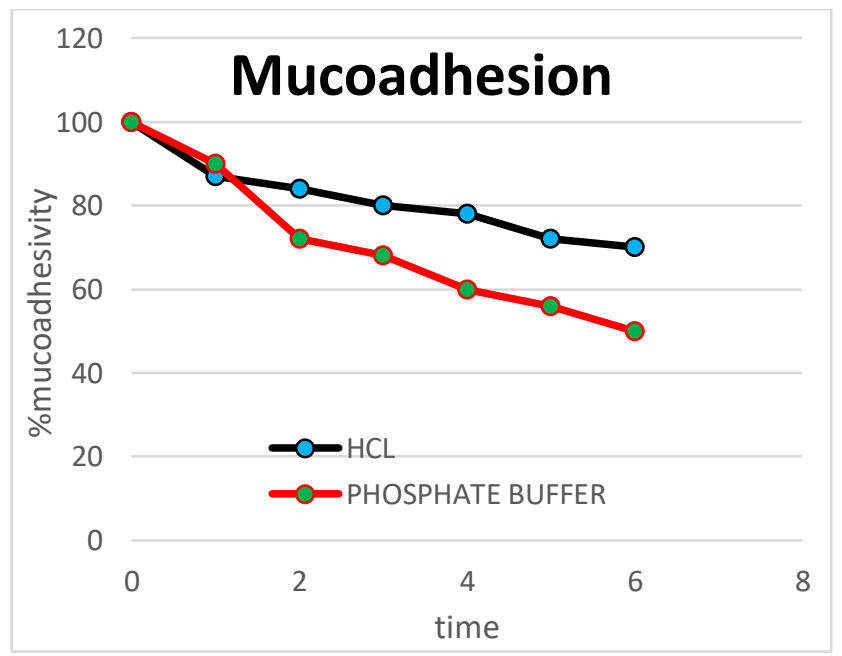

Fig.5 Mucoadhesivity of optimized formulation F3 


\subsection{In Vitro Drug Release Studies}

The In-vitro drug release for FSM -alginate beads containing Vildagliptin was carried out in $0.1 \mathrm{~N} \mathrm{HCL}$ for $1^{\text {st }}$ two hours and then in phosphate buffer for 8 hours. All the 6 formulations showed prolonged release over $10 \mathrm{~h}$. The drug release from the beads in acidic medium was slow due to the shrinkage of alginate in acidic $\mathrm{pH}(10.17 \%-20.04 \%)$. Due to the higher swelling rate in phosphate buffer drug release was found to be greater in phosphate buffer.(31.45\%$97.86 \%)$.

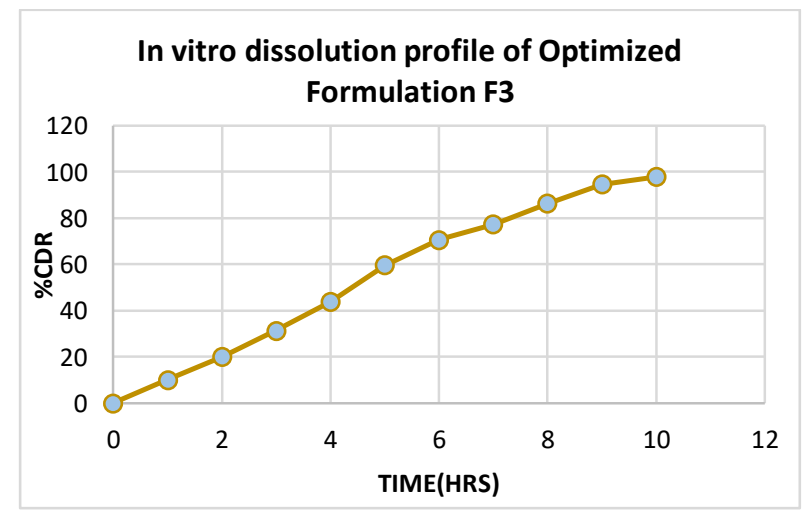

Fig.6 The In-vitro drug release of Optimized Formulation F3

3.8 Drug Release Kinetic Data:

\begin{tabular}{|c|c|c|c|}
\hline FORMULATIONS & ZERO ORDER & HIGUCHI & KOSMEYER PEPPAS \\
\hline F3 & $\mathbf{R}^{2}$ & $\mathbf{R}^{2}$ & $\mathbf{R}^{2}$ \\
\hline & 0.943 & 0.877 & 0.843 \\
\hline
\end{tabular}

The highest value of $\mathrm{R}^{2}$ indicates that the model follows zero order kinetics .For zero order $\mathrm{R}^{2}$ value was found to be: 0.943 .

\section{CONCLUSION:}

Mucoadhesive beads containing Vildagliptin made of FSMalginate polymer-blend by ionotropic gelation technique was successfully prepared and evaluated. The above studies suggested that the FSM-alginate mucoadhesive beads containing Vildagliptin swelled slowly in the stomach and accordingly adhered to the stomach mucosa allowing more drug to be absorbed minimizing the diffusion barriers to increase the absorption period by prolonging the gastric residence time. Then, these beads were subsequently move to the upper part of the intestine, where they swelled more and release the drug. The results demonstrated that the ability of the beads to maintain dense blood glucose level. Thus FSM is a potential mucoadhesive agent in the development of controlled release formulations.

\section{ACKNOWLEDGEMENTS:}

College Director: Dr Sr Betty Carla.

Principal: Dr Vinod B.

Guide: Dr Boby Jhons G.

\section{REFERENCES:}

1. Amit Kumar Nayak Dilipkumar Pal, Jyotiprakash Pradhana, and M.Saquib Hasania.et al: Fenugreek seed mucilage-alginate mucoadhesive beads of metformin $\mathrm{HCl}$ : Design, optimization and evaluation. International Journal of Biological Macromolecules (2012) 144-154.

2. J.S. Patil, M.V. Kamalapur, S.C. Marapur, D.V. Kadam, Ionotropic gelation and polyelectrolyte complexation: the novel techniques to design hydrogel particulate sustained, modulated drug delivery system: A review, Digest Journal of Nanomaterials and Biostructures 5 (2010) 241-248.
3. S. Racovita, S. Vasilu, M. Popa, C. Luca, Polysaccharides based micro- and nanoparticles obtained by ionic gelation and their applications as drug delivery systems, Revue Roumaine de Chimie 54 (2009) 709-718.

4. Tripathi KD. Essentials of Medical Pharmacology. 5thedition. New Delhi: Jaypee Brothers Medical Publications; 2003: p 266

5. https://www.drugbank

6. R. Dutta, A.K. Bandyopadhyay, Development of a new nasal drug delivery system of diazepam with natural mucoadhesive agent from Trigonella foenumgraecum L, Journal of Scientific and Industrial Research 64 (2005) 973-977.

7. Robinson JK, Vincent HLL. Controlled Drug Delivery Fundamentals and Applications. 2 nd edition. New York: Marcel Dekker Inc; 1968: p 346-74.

8. Jain NK. Targeted drug delivery system. 4th edition. New Delhi: CBS Publishers and Distributors. p 236-83.

9. Harshad Parmar, Sunil Bakliwal, Nayan Gujarathi, Bhushan Rane et al. Different methods of formulation and evaluation of mucoadhesive microsphere. IJABPT. 2010; 1(3): 1157-67.

10. Mathew Sam T, Devi Gayathri S, Prasanth V, Vinod B. Nsaids as Microspheres. The Internet Journal of Pharmacology 2008; 6(1): 332-338.

11. Pathiraja A, Adhikari R. Biodegradable Synthetic Polymers for Tissue Engineering. Europiean cell and materials 2003; 5: 116.

12. Gavin PA, Laverty TP, Jones DS. Mucoadhesive Polymeric Platforms for Controlled Drug Delivery. European Journal of Pharmaceutics and Biopharmaceutics 2009; 71: 505-518.

13. Hemalatha Kaurav, Hari Kumar SL, Amanpreet Kaur. Mucoadhesive Microspheres as carriers in Drug Delivery: A Review. Int J Drug Dev\&Res.2012; 4(2): 21-34.

14. Swarbrick J. Encyclopedia of Pharmaceutical Technology. Microsphere Technol Appl. 2007;3(4):2329.

15. Siddalingam $P$, Mishra $B$. Preparation and in vitro characterization of gellan based floating beads of acetohydroxamic acid for eradication of $\mathrm{H}$. pylori. Acta Pharm. 2007; 57:413-427. 
16. Reis C P, Neufeld R J. Design of insulin loaded alginate Nanoparticles: Influence of calcium ion on polymer gel matrix properties. CI\&CEQ. 2006;2:47-52.

17. Sapana P Ahirrao, Paraag S Gide B Shrivastav and Pankaj Sharma Ionotropic Gelation: A Promising Cross Linking Technique for Hydrogels. Research and reviews: journal of pharmaceutics and nanotechnology. 2014 jan-mar 2(1): 1-6

18. Bugarski, B., Li, Q., Goosen, M. F. A., Poncelet, D., Neufeld, R. J., \& Vunjak, G. Electrostatic droplet generation: Mechanism of polymer droplet formation. AIChE Journal, (1994) 40(6), 1026-1031.

19. Imran Abdul Kayyum Tadwee, Sadhana Shahi, Thube M, Ankit S. Review of Microspheres. IJPRAS. 2012; 1(1): 24-33.

20. Chowdhary K, Sundari P. Evaluation of Calcium Starch: A New Starch Based Polymer for Controlled Release of Diclofenac. International Journal Chem. Science 2008; 6 (3): 1189-1195.

21. Dahiya S, Tyagi L. Preparation and Evaluation of Oxytetracycline Hydrochloride Microbeads for Delayed Release. Pakistan Journal of Pharmceutical Science 2008; 21: 103-108

22. Prasad S, Raj M, Ajay M, Babu B, Audinarayana N, Reddy K, Mohanambal E. Formulation and Evaluation of Lamivudine Enclosed Alginate Microbead. Der Pharmacia Lettre 2011; 3(6): 294-304

23. Singhal P, Kumar K, Pandey M, Shubhini A. Evaluation of Acyclovir Loaded Oil Entrapped Calcium Alginate Beads Prepared by Ionotropic Gelation Method. International Journal of ChemTech Research 2010; 2: 2076-2085.
24. Goyal S, Vashist H, Gupta A, Jindal S, Goyal A. Development of Alginate Gel Beads-Entrapped Liposome for Colon Specific Drug Delivery of Prednisolone. Der Pharmacia Sinica 2010; 2(2): 31-38

25. Sangeetha S, Sakthisaravanan V, Komala M, Harish G, Sivakumar V. Design and Evaluation of Gastroretentive Beads of Theophylline by Ionotropic Gelation. International Journal of Pharmacy and Pharm aceutical Science 2010; 2: 99-101

26. Prasanth V, Chakraborty A, Mathew S, Parthasarathy G, Mathappan R, Thoppil S. Formulation and Evaluation of Salbutamol Sulphate - Alginate Microspheres by Ionotropic Gelation Method. International journal of comprehensive pharmacy 2011; 7: 1-7.

27. Alagasundaram, M.et al,Microspheres as a novel drug delivery system,- A review, International Journal of ChemTech Research,(2009) 526-534.

28. Gupta, P. K., and Hung, C. T. Albumin microspheres. Vs Evaluation of parameters controlling the efficacy of magnetic microspheres in the targeted delivery of adriamycin in rats. Int. J. Pharm.(1990) 59:57-67.

29. N. M., and Mano , J. F.Chitosan coated alginate beads containing poly (Nisopropylacrylamide) for dual-stimuliresponsive drug release. J. Biomed. Mater. Res. B Appl. Biomater .(2007) 84:595-603.

30. S.P. Vyas and R.K.Khar, Targeted and Controlled drug delivery, 07 th Edition, 418-457. 